\title{
Segundo registro de Sterrastrolepis brasiliensis Volkmer-Ribeiro \& De Rosa-Barbosa (Demospongiae, Potamolepidae) com descrição do habitat e de assembléia, Bacia do Rio Paraná, Brasil
}

\author{
Cecília Volkmer-Ribeiro ${ }^{1} \&$ Mauro Parolin ${ }^{2}$ \\ ${ }^{1}$ Museu de Ciências Naturais, Fundação Zoobotânica do Rio Grande do Sul. Caixa Postal 1188, 90001 -970 Porto Alegre, \\ Rio Grande do Sul, Brasil. Pesquisadora bolsista do CNPq. E-mail: cvolkmer@fzb.rs.gov.br \\ ${ }^{2}$ Faculdade Estadual de Ciências e Letras de Campo Mourão. Avenida Comendador Norberto Marcondes 733, 87303-100 \\ Campo Mourão, Paraná, Brasil. E-mail: mauroparolin@gmail.com
}

\begin{abstract}
Second register of Sterrastrolepis brasiliensis Volkmer-Ribeiro \& De Rosa-Barbosa (Demospongiae, Potamolepidae) with description of the habitat and of assembly, Paraná Basin, Brazil. The recent discovery of Sterrastrolepis brasiliensis Volkmer-Ribeiro \& De Rosa-Barbosa, 1978, a brazilian endangered freshwater sponge, at the rocky bottom of River Piquiri, Paraná Basin, Brazil, enhanced the photographing of living specimens, the improving of SEM illustration and description for some characteristics, the description of the habitat and the register of an sponge assembly composed by S. brasiliensis, Oncosclera navicella (Carter, 1881) and Oncosclera tonolli (Bonetto \& Ezcurra de Drago, 1968). Oncosclera tonolli has its first register for Brazilian waters and for the Parana Basin. Gemmules of 0 . navicella are also SEM illustrated.
\end{abstract}

KEY WORDS. Endangered species, freshwater sponges, rocky bottom, South America.

RESUMO. A descoberta recente, no fundo rochoso do Rio Piquiri, Bacia do Paraná, Brasil, de Sterrastrolepis brasiliensis Volkmer-Ribeiro \& De Rosa-Barbosa, 1978, uma espécie de esponja continental ameaçada, possibilitou o registro fotográfico de espécimes vivos, o aperfeiçoamento das ilustrações ao MEV e da descrição de algumas características, a descrição do habitat e o registro de uma assembléia de esponjas composta por S. brasiliensis, Oncosclera navicella (Carter, 1881) e Oncosclera tonolli (Bonetto \& Ezcurra de Drago, 1968). Oncosclera tonolli tem seu primeiro registro para águas brasileiras e para a Bacia do Paraná. Gêmulas de 0 . navicella são tambem ilustradas ao MEV.

PALAVRAS CHAVE. América do Sul, espécies ameaçadas, esponjas de água doce, fundo rochoso.

A descrição original de Sterrastrolepis brasiliensis Volkmer-Ribei-
ro \& De Rosa-Barbosa, 1978, foi baseada sobre apenas dois exem-
plares, o holótipo, proveniente do rio Turvo (afluente do rio
Paranaíba) na localidade de Paraúna-Goiás e um parátipo, pro-
veniente do rio Itararé (afluente do rio Paranapanema) na loca-
lidade de Carlópolis-Paraná (e não Carbópolis como registrado).
A singularidade dos materiais justificou a proposição do novo
gênero Sterrastrolepis Volkmer-Ribeiro \& De Rosa-Barbosa, 1978,
de esponjas de água doce, restrito portanto à Bacia do Rio Paraná.
A descrição original foi ilustrada apenas com desenhos das
megascleras e gemoscleras em câmara lúcida. EzcuRRA DE DRAGo
(1978) descreveu e ilustrou sumariamente Stratospongilla
brasiliensis, com as mesmas características espiculares de
Sterrastrolepis brasiliensis Volkmer-Ribeiro \& De Rosa-Barbosa,
1978, e mesmo registro de localidade tipo, baseado no mesmo
material de Sterrastrolepis brasiliensis, logo um sinônimo. Poste-
riormente VolkMER-RIBEIRo \& DE Rosa-BARBosa (1979), forneceram
fotografias do holótipo e do parátipo de Sterrastrolepis brasiliensis, da estrutura do esqueleto, além de fotos em microscopia óptica dos conjuntos espículares. Nesse trabalho as autoras posicionaram o novo gênero dentro da família Potamolepidae Brien, 1967, então extendida da região Etiópica à região Neotropical, contendo, além de Sterrastrolepis os gêneros Uruguaya Carter, 1881, Potamolepis Marshall, 1883, Potamophloios Brien, 1970, Stratospongila Annandale, 1909 e Oncosclera Volkmer-Ribeiro, 1970. Essa proposição foi ratificada por MANCONI \& PRONZATO (2002), que ofereceram fotos em microscopia de varredura das espículas e de uma gêmula de Sterrastrolepis brasiliensis, essa obtida por empréstimo da coleção de Porifera do MCN/FZB e seccionada. Até esse momento não se tinha conhecimento do habitat da espécie, julgando-se que pertencesse à fauna bêntica de fundo rochoso em águas turbulentas, uma vez que os dois espécimes, com consistência extremamente dura, haviam sido destacados sem maiores cuidados do substrato, contendo apenas o holótipo a sua placa basal, com raras gêmulas a ela aderidas. Dada a inexistência de data de coleta e precisão do local de ori- 
gem do holótipo e parátipo, aliada à ausência de novos registros, Sterrastrolepis brasiliensis foi incluída na recente lista da fauna brasileira ameaçada (BrAsIl 2004). Deveu-se essa inclusão ainda ao fato de que o rio Itararé teve suas águas barradas pela Represa de Xavantes, na localidade de Carlópolis, o que deve ter contribuído para a redução da ocorrência de Sterrastrolepis brasiliensis no local, já que o ambiente passou de lótico a lêntico. Em agosto de 2004 o autor junior foi abordado por residentes da localidade de Porto Bananeira, distrito de Campina da Lagoa-Paraná, para que identificasse material que estava causando ferimentos nos pés dos residentes, que buscavam o rio em atividades de lazer e pesca. Havendo-se reconhecido a espécie, foi providenciado de imediato o reconhecimento da área e realizada amostragem mais representativa e observação de características "in situ", visando ainda o conhecimento do habitat e de eventuais outras esponjas associadas. Tendo em vista a reduzida definição das fotos ao MEV apresentadas por MANCONI \& PRonZato (2002), foi providenciada uma outra série de ilustrações, conducentes a correção de alguns termos utilizados por esses autores, além de confirmação e ampliação de características originalmente descritas.

\section{MATERIAL E MÉTODOS}

Foram realizadas duas excursões (19/08/2004 e 26/11/ 2004) na área de ocorrência da esponja no rio Piquiri (Fig. 1) e tomadas "in situ", com equipamento potenciométrico digital, medidas de $\mathrm{pH}$, Oxigênio dissolvido e temperatura da água. Na segunda excursão coletaram-se amostras de água para determinação do percentual de sílica (método do silicomolibdato adaptado do Standard Methods, American Public Health Association (1992)). Os exemplares foram coligidos com os substratos, a fim de que o exame desses permitisse a constatação de associações, indicadas geralmente por gêmulas de espécies concorrentes. Para exame das espículas ao microscópio óptico e de varredura (MEV) seguiu-se Volkmer-Ribeiro \& Turce (1996). Os espécimes estudados estão depositados e catalogados na coleção de Porifera do Museu de Ciências Naturais da Fundação Zoobotânica do Rio Grande do Sul (MCN-FZB). As imagens ao MEV das gêmulas de Sterrastrolepis brasiliensis e de Oncosclera navicella foram realizadas no Centro de Microscopia Eletrônica da PUCRS, Porto Alegre, RS e as das gemoscleras de Sterrastrolepis brasiliensis no Centro de Microscopia Eletrônica e Microanálise da ULBRA, Canoas, Rio Grande do Sul. As fotografias em microscopia ótica foram feitas no Laboratório de Apoio do Integrado Colégio e Faculdade de Campo Mourão-Paraná. Para obtenção das medidas das espículas de materiais de $S$. brasiliensis agora coligidos, foram aferidas 50 espículas de cada categoria (Tab. I).

\section{RESULTADOS}

\section{Caracterização da área de ocorrência e do habitat}

MAACK (2002), relata que o rio Piquiri nasce na "Serra São João" (1.237 m), que é um divisor de águas em forma de mesetas entre os rios Piquiri, Ivaí e o sistema do rio Jordão. Segundo esse

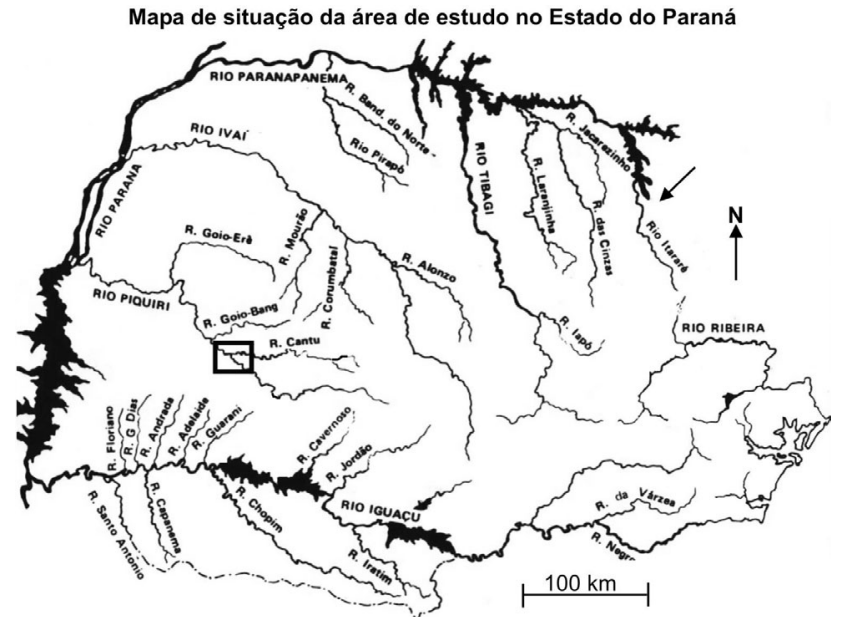

Figura 1. Mapa de situação da área de ocorrência de Sterrastrolepis brasiliensis no rio Piquiri. A seta aponta para o rio Itararé, um dos locais do primeiro registro da espécie. Adaptado de MAACK (2002).

mesmo autor, o rio percorre uma extensão aproximada de 485 km, e seus principais afluentes são: Cantu, Goi-Bang e Goio-Erê pela margem direita e o rio do Cobre pela margem esquerda.

Segundo Justos (1990) o rio Piquiri apresenta um traçado leste-oeste, constituindo um rio cataclinal de reverso. O seu talvegue é simples e está encaixado num vale limitado por encostas íngremes com dissecação intensa ao longo do vale, em seus cursos médio e superior, enquanto em seu curso inferior, próximo à foz, forma terraços de várzea que alcançam, em alguns pontos, $1 \mathrm{~km}$ de largura. Apresenta grande quantidade de corredeiras e quedas d'água em seu curso médio e superior.

O local acessado foi georeferenciado em $24^{\circ} 45^{\prime} \mathrm{S}-52^{\circ} 52^{\prime} \mathrm{W}$, na localidade de Porto Bananeira, município de Campina da Lagoa, área de travessia de balsa da rodovia PR 471 (Fig. 2), divisa dos municípios de Campina da Lagoa e Guaraniaçu.

Estima-se que essa ocorrência estenda-se no curso médio do rio Piquiri, desde as corredeiras, situadas a montante da foz do rio Cantu, até aproximadamente $7 \mathrm{~km}$ a jusante. O leito do rio desenvolve-se sobre afloramentos basálticos, com presença freqüente de corredeiras, ocasionando águas turbulentas. "O relevo, em praticamente toda a extensão do rio Piquiri, é constituído por patamares e mesetas" (PARANÁ 1990: 10). Com relação ao domínio geológico, a área se encontra sobre rochas efusivas básicas, originadas na era Mesozóica (Juracretáceo), KAUL (1990), com a predominância de basaltos da formação Serra Geral.

Os solos da região não oferecem potencial agrícola, pois há impedimento de mecanização por relevo e pedregosidade, bem como alta susceptibilidade à erosão, destacando-se também o fato do excesso de alumínio trocável, Moser (1990). Na localidade acessada pelas expedições predomina atualmente a atividade pastoril.

LeITE \& KLEIN (1990) destacam a predominância, na re- 

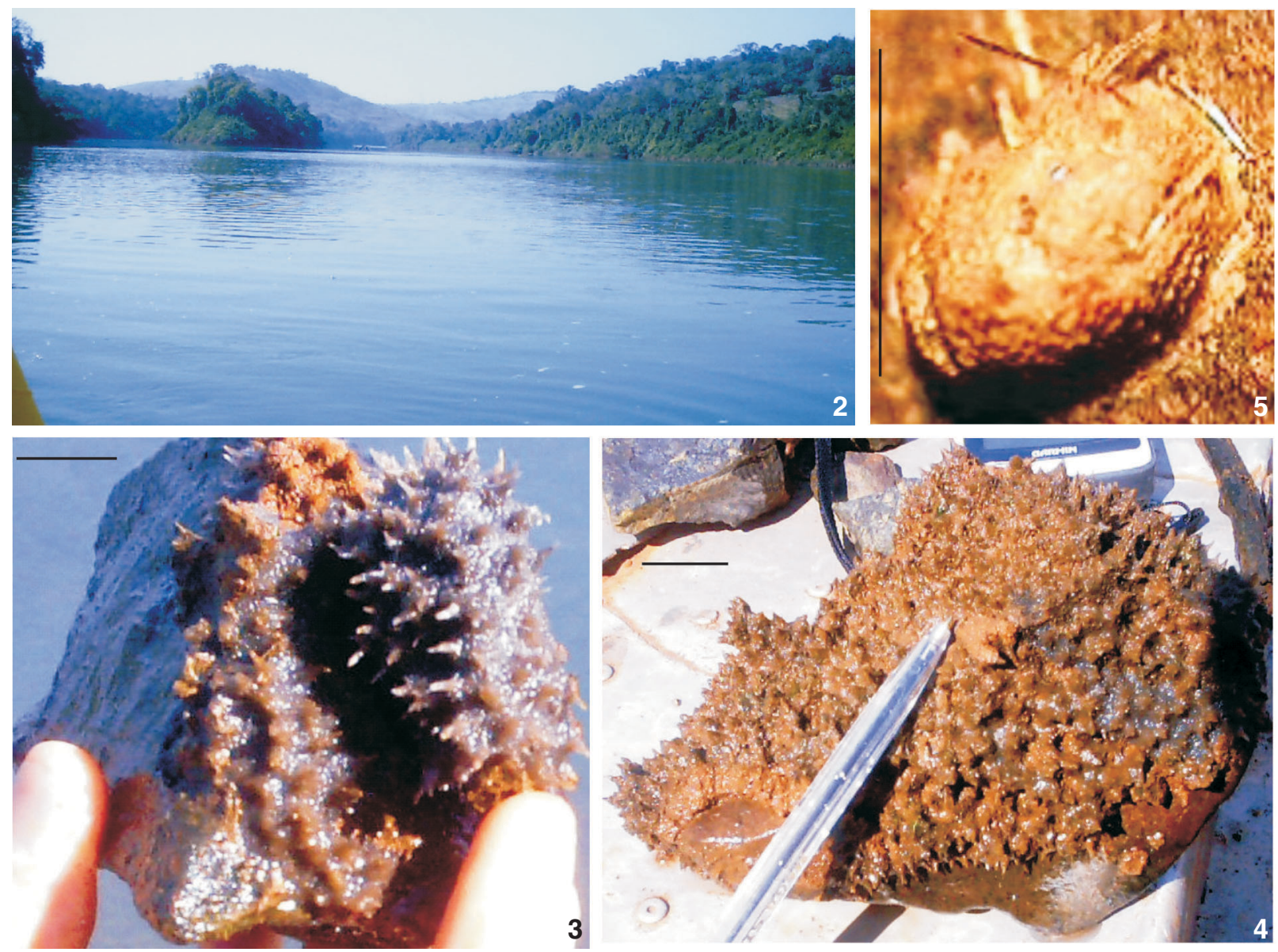

Figuras 2-5. (2) Rio Piquiri - a amostragem de S. brasiliensis foi realizada a jusante da ilha vista na porção superior da foto; (3-5) Sterrastrolepis brasiliensis: (3-4) exemplares vivos, escala $1 \mathrm{~cm}$; (5) gêmula "in situ" no substrato rochoso, revelando as reentrâncias que correspondem as áreas foraminais, escala $1 \mathrm{~mm}$. Fotos Mauro Parolin.

Tabela I.Comparação das dimensões em micrômetros das espículas de S. brasiliensis, conforme descrição original (MCN 113 e MCN 116) e do material do rio Piquiri (MCN 6364 e MCN 6366).

\begin{tabular}{|c|c|c|c|c|c|c|c|}
\hline \multirow{2}{*}{ Exemplares } & & \multicolumn{2}{|c|}{ Megascleras } & \multicolumn{2}{|c|}{ Microscleras } & \multicolumn{2}{|c|}{ Gemoscleras } \\
\hline & & Comprimento & Largura & Comprimento & Largura & Comprimento & Largura \\
\hline \multirow[t]{3}{*}{ MCN 113} & Máximo & 508,20 & 49,90 & 136,50 & 6,60 & 53,20 & 26,60 \\
\hline & Média & 415,40 & 40,80 & 109,70 & 6,20 & 42,20 & 22,50 \\
\hline & Mínimo & 324,80 & 29,10 & 83,20 & 4,90 & 33,30 & 19,90 \\
\hline \multirow[t]{3}{*}{ MCN 116} & Máximo & 508,10 & 53,30 & 156,50 & 9,90 & & \\
\hline & Médio & 432,70 & 38,00 & 112,60 & 6,30 & & \\
\hline & Mínimo & 333,20 & 24,90 & 89,90 & 4,90 & & \\
\hline \multirow[t]{3}{*}{ MCN 6366} & Máximo & 470,40 & 37,42 & 135,57 & 6,20 & 45,93 & 22,30 \\
\hline & Média & 369,24 & 26,27 & 106,46 & 4,50 & 37.32 & 18,79 \\
\hline & Mínimo & 289,20 & 20,68 & 74,70 & 3,19 & 30,00 & 14,10 \\
\hline \multirow[t]{3}{*}{ MCN 6364} & Máximo & 821,70 & 75,40 & 157,30 & 7,20 & 44,64 & 23,40 \\
\hline & Médio & 730,25 & 60,49 & 114,93 & 5,07 & 38,59 & 19,02 \\
\hline & Mínimo & 512,00 & 45,20 & 82,10 & 2,00 & 31,00 & 14,10 \\
\hline
\end{tabular}

Revista Brasileira de Zoologia 22 (4): 1003-1013, dezembro 2005 

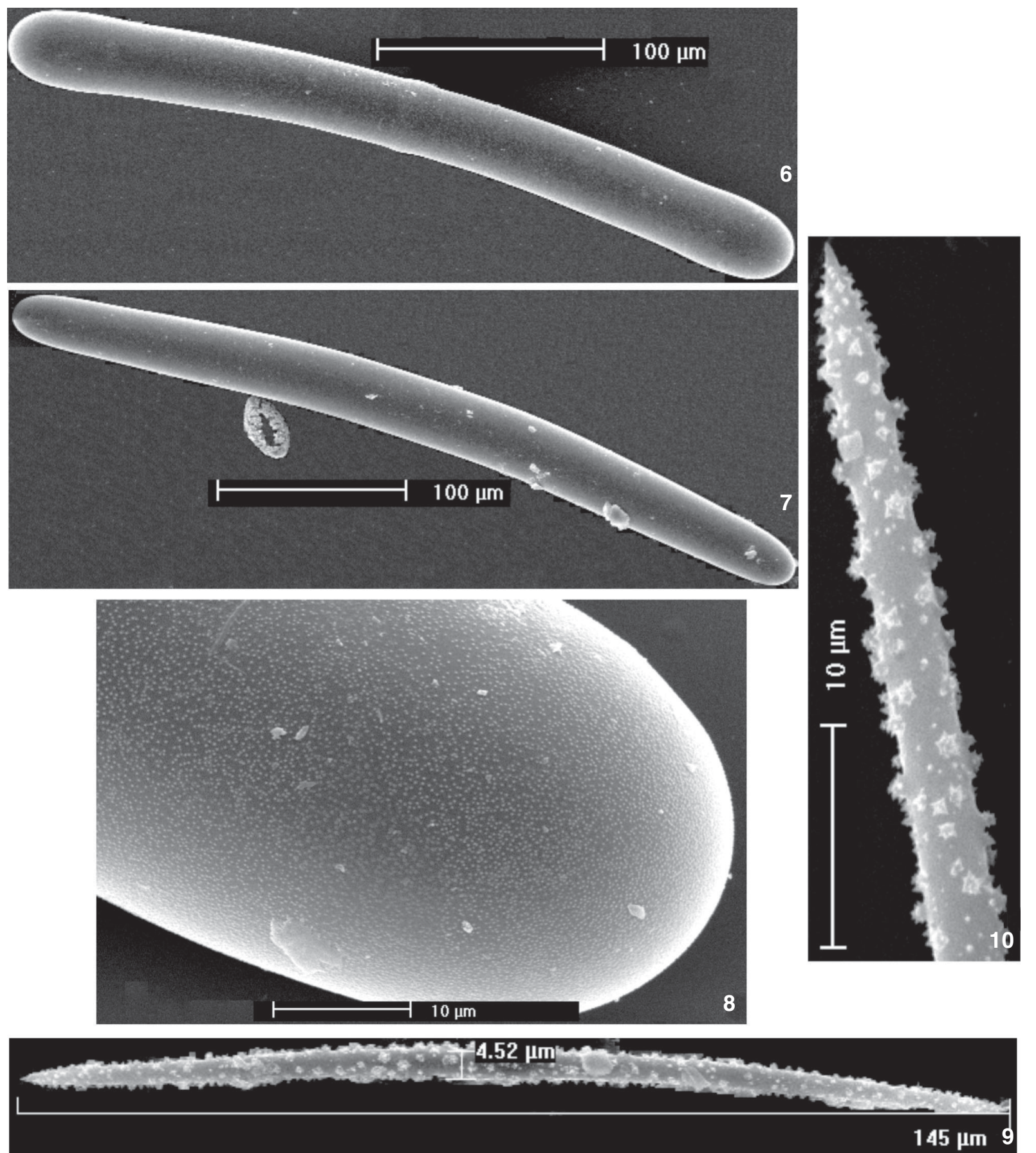

Figuras 6-10. Sterrastrolepis brasiliensis: (6) megasclera anfistrôngilo com extremidades infladas; (7) megasclera e gemosclera; (8) detaIhe de megasclera evidenciando a superfície microgranulada; (9) microsclera; (10) detalhe da extremidade da microsclera.

gião, da Floresta Estacional Semidecidual, entretanto secundária, associada à atividade agropecuária.

Na região de estudo a pluviosidade situa-se entre 1.600 a
1.800 mm anuais, MAACK (2002), Nimer (1990) e PARANÁ (1990), sendo os meses menos chuvosos abril, julho e agosto. "O clima característico é o Cfa com verão quente (> 22 ${ }^{\circ}$ )" (PARANÁ 1990: 20).

Revista Brasileira de Zoologia 22 (4): 1003-1013, dezembro 2005 


\section{Qualidade da Água}

Na data da primeira campanha (19/08/2004 - estação seca) a água do rio apresentava-se transparente, permitindo visualizar as esponjas a olho nú (1 $\mathrm{m}$ de profundidade). Os parâmetros limnológicos aferidos foram: temperatura da água $\left(19,3^{\circ} \mathrm{C}\right) ; \mathrm{pH}(6,0)$ e oxigênio dissolvido $(8,5 \mathrm{mg} / \mathrm{L})$. Em data da segunda campanha (25/11/2004 - estação chuvosa) o rio apresentava forte correnteza e nível de água mais elevado do que na campanha anterior, cor avermelhada e reduzida transparência, resultado do transporte de sedimento, impossibilitando a visualização das esponjas. Nessa ocasião registraram-se os seguintes parâmetros: temperatura $26,2^{\circ} \mathrm{C}$; pH 7,0; oxigênio dissolvido 8,5 mg/L e 19,0 mg/L de sílica dissolvida.

\section{A Assembléia de Esponjas}

Sterrastrolepis brasiliensis é a espécie de esponja dominante no local, seguida em abundância por Oncosclera navicella e $O$. tonolli (Bonetto \& Ezcurra de Drago, 1968), caracterizando portanto o ambiente como favorecedor da ocorrência de esponjas da Familia Potamolepidae. A primeira forma crostas cinzaazuladas, extensas e extremamente híspidas, na face superior e lateral dos substratos rochosos, em locais de água mais oxigenada a jusante das corredeiras. A segunda forma de crostas delgadas a grupamentos de gêmulas, geralmente na parte inferior dos substratos, em contato com o leito do rio, soldando pedregulhos às pedras maiores ou ainda pequenos nódulos na base das incrustações de Bryophita nas corredeiras. O. tonolli forma crostas finas, pequenas ou grupamentos de gêmulas ou gêmulas isoladas, coladas em reentrâncias das pedras, nas porções laterais mais resguardadas dos substratos. Acredita-se que essa assembléia possa ser composta por mais espécies do que as detectadas, uma vez que as prospecções foram pontuais, devido à restrição de amostragem, determinada pelo fato de $S$. brasiliensis constar da lista da fauna ameaçada do país e dessas esponjas ocorrerem juntas nos mesmos substratos. São abordadas a seguir as peculiaridades notadas para cada uma das referidas espécies. O. tonolli tem seu primeiro registro para o Brasil e para a bacia do rio Paraná, pois a espécie foi descrita e registrada por BonetTTo \& EzCURRA DE Drago (1968), para a Bacia do Rio Uruguai.

\section{Sterrastrolepis brasiliensis Volkmer- Ribeiro \& De Rosa-Barbosa, 1978 Figs 3-22}

Sterrastrolepis brasiliensis Volkmer Ribeiro \& De Rosa-Barbosa, VI-1978: 103-107, fig. 1; Volkmer Ribeiro \& De Rosa-Barbosa, 1979: 508-509, figs 3-9; Manconi \& Pronzatto, 2002: 1011-1013; Brasil, 2004: 137.

Stratospongilla brasiliensis Ezcurra de Drago, XII-1978: 105-110. Syn. nov.

Localidade tipo. Rio Turvo, contribuinte do Paranaíba, localidade de Paraúna, Estado de Goiás, Brasil.

Nome popular. Espinho de Pedra. O nome foi cunhado pelos residentes da localidade de Porto Bananeira, que utilizam o rio em suas atividades de lazer durante o verão, pois nessa ocasião o nível do rio é baixo e a água cristalina. Dada a dureza e hispidez, as projeções da superfície da esponja, que chegam a formar cristas em arcos sobre o substrato (VolKMERRibeiro \& De Rosa-Barbosa 1979: figs 5 e 6), causam ferimentos nos pés dos banhistas e pescadores. Informações colhidas localmente revelaram que essas projeções, denominadas de "castelinhos", são colecionadas pelos residentes e às vezes ainda cobertas por tinta, ao gosto do colecionador.

Material examinado. Ezquizolótipo MCN-POR 113, rio Turvo, Paraúna, Goiás, Brasil; Ezquizoparátipo MCN-POR 116, rio Itararé, Carlópolis, Paraná, Brasil W.Nunes leg. MCN-POR 6192 rio Piquiri, Porto Bananeira, Campina da Lagoa, Paraná, Brasil, Elaine A. Luiz leg.; MCN-POR 6287; 6364; 6366; 6371, rio Piquiri, Porto Bananeira, Campina da Lagoa, Paraná, Brasil, 18/08/2004, M. Parolin e V.Alves leg.; MCN-POR 6368, rio Piquiri, Porto Bananeira, Campina da Lagoa, Paraná, Brasil, 25.XI. 04, C. Volkmer Ribeiro leg.

Descrição. A esponja ocorre preferencialmente na face superior dos substratos rochosos, mas forma também crostas finas ou grumos em quaisquer substratos rígidos, sobre ou entre as pedras, como a vegetação submersa de Bryophita, a carapaça de gastrópodes e bivalves ou fragmentos lenhosos de vegetação. Nos substratos rochosos contínuos a esponja forma crostas extensas, volumosas e extremamente duras e híspidas, com projeções cônicas bifurcadas, trifurcadas, polifurcadas, chegando a soldarem-se em arcos. Os espécimes tem cor cinzaazulada, passando à avermelhada pelo acúmulo de sedimento do rio (Figs 3-4). O pinacoderma é conspícuo, ósculos numerosos orientados no sentido da correnteza (Fig. 4). Gêmulas não aparentes, abundantes, situadas na base da esponja e individulamente soldadas ao substrato ou visíveis, isoladas do esqueleto e coladas em reentrâncias do substrato (Fig. 5). Megascleras anfistrôngilos robustos com as extremidades eventualmente infladas (Figs 6-7), microgranulados (Fig. 8) levemente curvos. Microscleras oxeas longas levemente curvas, densamente espinhadas com extremidades abruptamente aguçadas (Figs 9-10). Gêmulas grandes, de forma mamilar, individualmente coladas ao substrato e circundadas na base por algumas megascleras, que não constituem, no entanto, cápsulas. A superfície é irregular, devido à projeção dos esterrasters, geralmente três áreas foraminais, colocadas em reentrâncias da superfície e providas de dois orifícios foraminais, esses desprovidos de tubo foraminal (Figs 5, 11 e 16). Em corte transversal (Figs 12-15) as gêmulas evidenciam uma capa externa fina, uma grossa camada pneumática (161 micrômetros) consituída por câmaras aéreas diminutas, circulares e regulares e uma camada interna também delgada, além de uma abundante massa de arqueócitos, contidos numa estrutura favosiforme circular, contígua à camada interna da gêmula (Figs 12-15). As gemoscleras constituem diversos estratos, mergulhadas de modo irregular na camada pneumática. Gemoscleras esterrasteres, de elipsóides 

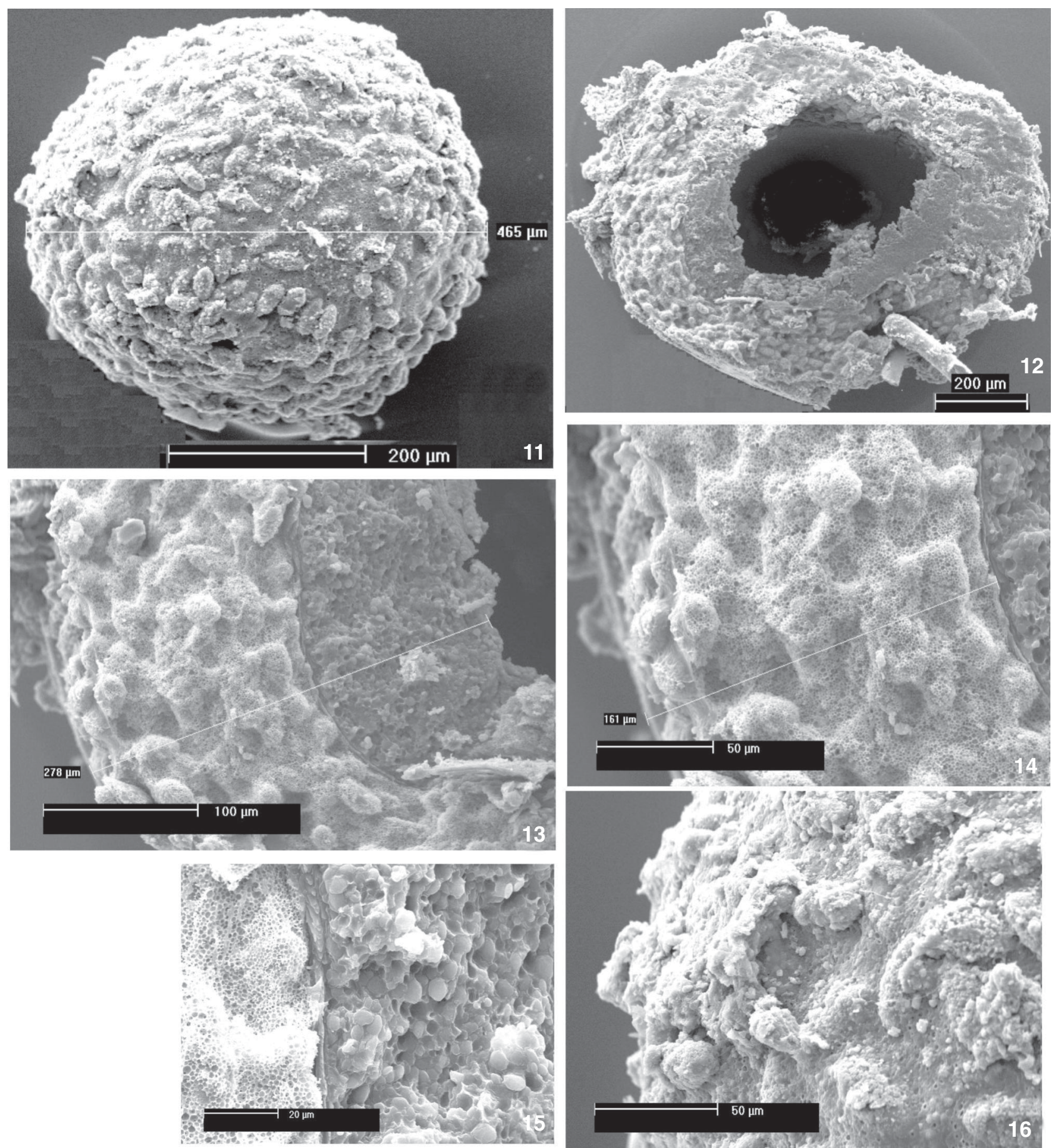

Figuras 11-16. Gêmulas de Sterrastrolepis brasiliensis: (11) gêmula inteira com uma área foraminal perceptivel à esquerda; (12) gêmula em corte transversal evidenciando a espessura da camada pneumática e da que contém os arqueócitos, a primeira completamente incrustada de sterrasters; (13) ampliação da parede da gêmula cortada vista na fig. 12, focando parte da camana pneumática, a fina camada interna e a estrutura em favos que contêm os arqueócitos; (14) ampliação da camada pneumática vista na figura anterior, evidênciando sua espessura e os diversos estratos de sterrasters; (15) ampliação da área de contato entre a camada pneumática, a camada interna da gêmula e a camada estruturada em favo que contêm os arqueócitos; (16) Ampliação da área foraminal vista na figura12 revelando os orifícios foraminais.

Revista Brasileira de Zoologia 22 (4): 1003-1013, dezembro 2005 


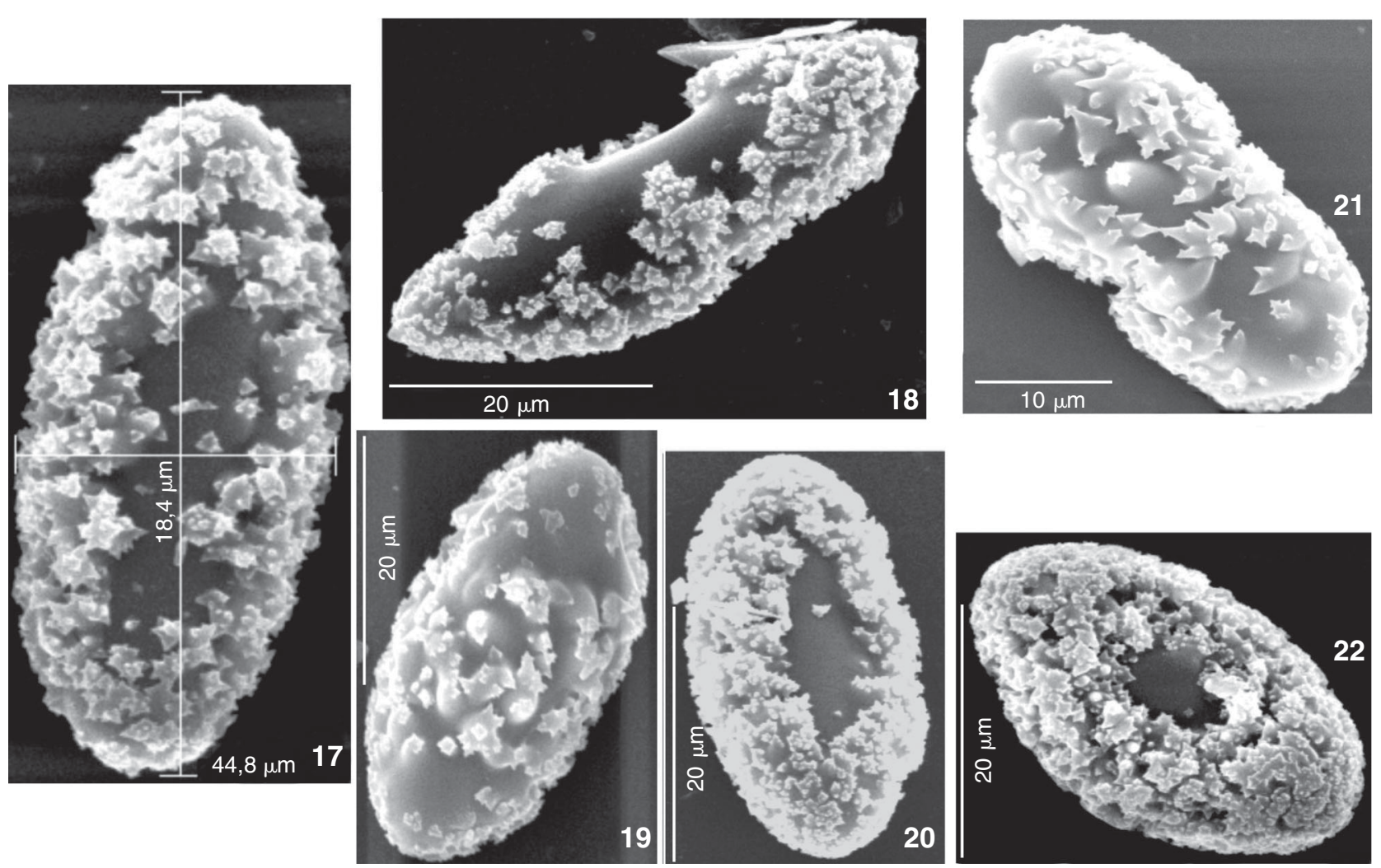

Figuras 17-22. Sterrastrolepis brasiliensis, variações da forma elipsóide e progressão da extrusão da espinhadura dos sterrasters, evidenciandos os estágios finais 17, 20 e 22 em que apenas o hylum aparece desprovido de espinhadura.

a esféricas, sempre apresentando um hilo, maior ou menor, conforme progride a extrusão de espinhos, desenvolvendo-se esses como coroas espinhadas, confluentes, chegando a ocupar quase toda a superfície da esclera, quando o hilo reduz-se então a um pequeno círculo (Figs 17-22).

A tabela I contém as dimensões das espículas dos espécimes originalmente descritos e daqueles do rio Piquiri.

Habitat. Conforme a descrição acima operada.

Distribuição. O presente registro amplia a distribuição da espécie do Estado de Goiás (rio Turvo) ao centro-oeste do Estado do Paraná (rio Piquiri), mantendo-a restrita, até o presente, à Bacia do rio Paraná.

Comentários. A singularidade, agora ampliada, das características da espécie são de tal monta, que ratificam novamente o status do gênero Sterrastrolepis, como aliás aceito por Manconi \& Pronzato (2002) justificando-se a sinonímia aqui proposta para Stratospongilla brasiliensis Ezcurra de Drago, 1978. Essas singularidades vêm-se agora multiplicadas com a descrição, nas gêmulas, de áreas foraminais, onde se alojam os forâmines (Figs 5, 11-16), e de uma camada estruturada, interna à gêmula, portadora dos arqueócitos (Fig. 15), características até agora não observadas em qualquer outra esponja dulcícola gemuliforme. A amostragem de espécimes vivos, ade- ridos aos substratos, permitiu constatar abundância de gêmulas, tanto nos espécimes, quanto isoladas no substrato, levando a que se surpreendessem gemoscleras em formação. Esse estudo conduziu à ilustrução do desenvolvimento dessas escleras e à confirmação de sua descrição original como esterrasteres (Figs 17-22), conforme a definição desses oferecida por BourY-EsNAUlT \& RüTZler (1997). Dado que a base de definições das estruturas adotada no Systema Porifera foi a proposta por BourY-EsNAulT \& RüTZler (1997), careceu de necessidade e de precisão a descrição das gemoscleras de $S$. brasiliensis, operada por MANCONI \& Pronzato (2002), como estrôngilos com uma superfície irregular. Confirma-se aqui a descrição feita por esses autores da camada pneumática de $S$. brasiliensis, grossa e provida de espaços aéreos regulares (Figs 12-14).

\section{Oncosclera navicella (Carter, 1881) Figs 23-28}

Spongilla navicella Carter, 1881: 87, est. 5, fig. 4 a-g. Oncosclera navicella; Tavares \& Volkmer-Ribeiro, 1997: 103-105, figs 11-14,16 (redescrição e sinonímia); Manconi \& Pronzato, 2002: 1008; Batista \& Volkmer-Ribeiro, 2002: 132; Pinheiro et al., 2003: 3-6, figs 2,a-c.; Batista et al., 2003: 531.

Material examinado. MCN-POR 6369, 6375, rio Piquiri, 


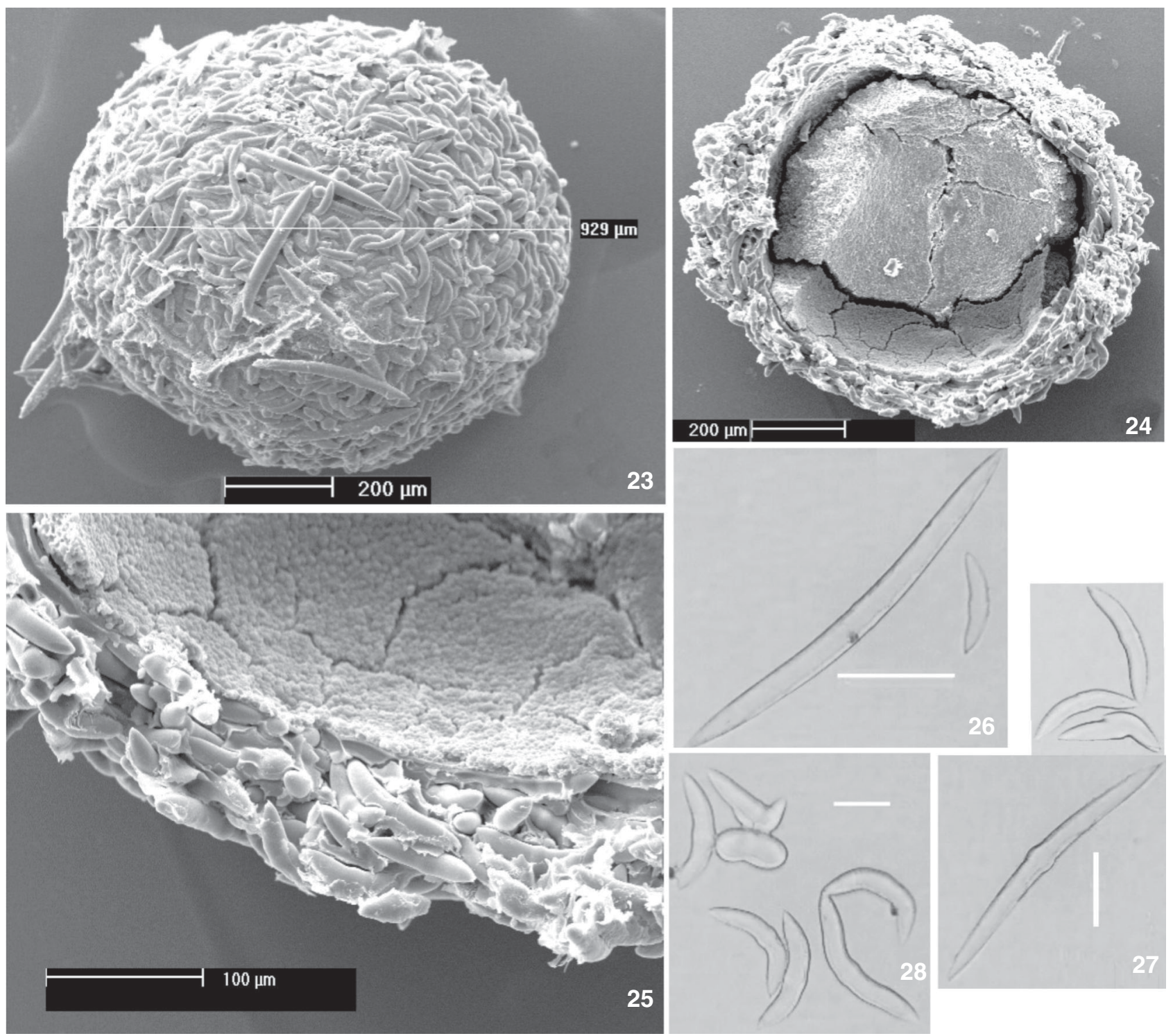

Figuras 23-28. Oncosclera navicella: (23) gêmula inteira; (24) gêmula em corte transversal; (25) ampliação da parede gêmular vista na figura 24 evidênciando ausência de camada pneumática; (26-28) megascleras e gemoscleras, fotografadas ao microscópio ótico. Fotos Mauro Parolin, escalas: $100 \mu \mathrm{m}$ (foto 26 ) e $40 \mu \mathrm{m}$ (fotos 27 e 28).

Porto Bananeira, Campina da Lagoa, Paraná, Brasil, 18/08/2004, M. Parolin e V.Alves leg.; MCN-POR 6367,6368, rio Piquiri, Porto Bananeira, Campina da Lagoa, Paraná, Brasil, 25.XI.04, C. Volkmer Ribeiro leg.

Localidade tipo. Rio Amazonas.

A espécie ocorreu formando crostas delgadas, de cor creme, ou como grupamentos de gêmulas, grandes, visíveis a olho nú e com incrustação de algumas megascleras. Os espécimes localizam-se na parte inferior dos substratos rochosos, em contato com o leito do rio, soldando pedras ou areia grossa entre sí. As crostas um pouco mais grossas contém gêmulas menores, situadas no meio do esqueleto, além dos estratos basais de gêmulas. As gêmulas conformam-se à redescrição operada por VOLKMERRiBeIro (1970), por ocasião da proposição do gênero Oncosclera Volkmer-Ribeiro, 1970, mostrando-se desprovidas de camada pneumática e com vários estratos de gemoscleras, soldadas entre si por espongina, continua à camada interna da parede gemular. Algumas megascleras podem ocorrer soldadas na superfície da gêmula (Figs 23-25). Arqueócitos abundantes constituindo uma massa que preenche todo interior da gêmula (Fig. 24).

Revista Brasileira de Zoologia 22 (4): 1003-1013, dezembro 2005 

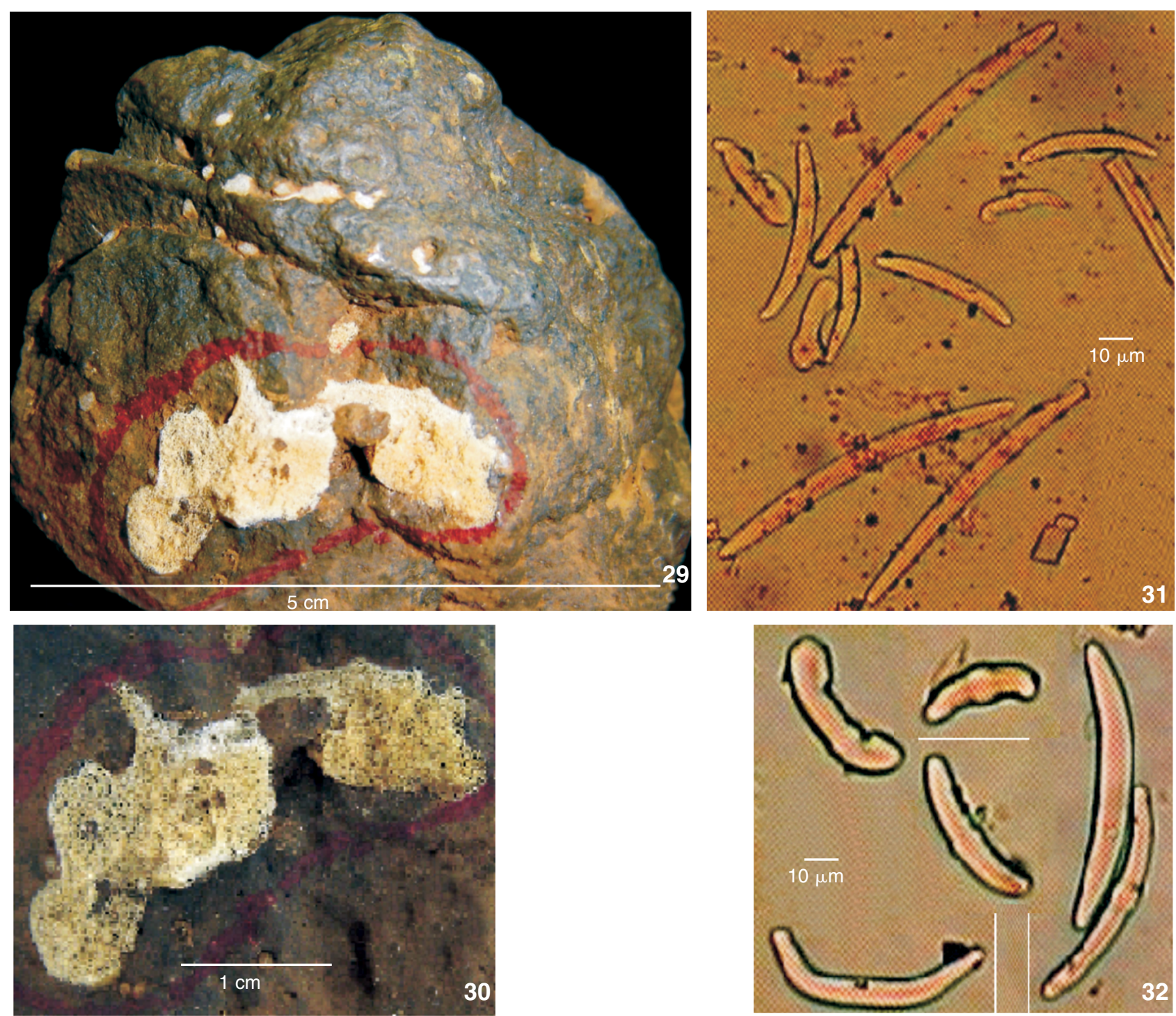

Figuras 29-32. Oncosclera tonolli: (29) exemplar MCN-POR 6370; (30) mesmo exemplar da figura 29 em detalhe; (31-32) conjunto de megascleras e gemoscleras fotografadas ao microscópio óptico. Fotos Vanessa de Souza Machado.

Distribuição. O. navicella tem ampla distribuição no continente Sul Americano, ocorrendo da Venezuela (VOLKMER-RIBeiro \& Pauls 2000), até a Argentina, (BonetTo \& Ezcurra de Drago 1967).

Comentários. O. navicella caracteriza-se como uma espécie típica de fundos rochosos, em águas rápidas e bem oxigenadas. Excepcionalmente, como apontado por BATISTA et al. (2003), ocupa substratos vegetais em várzeas inundadas, formando então apenas gêmulas isoladas, como descrito originalmente por CARTER (1881), e geralmente de cor preta, devido à exposição aérea. Nessa condição essas gêmulas só são percebidas por pesquisadores muito familiarizados com essa fauna.

\section{Oncosclera tonolli (Bonetto \& Ezcurra de Drago, 1968)}

Figs 29-32

Spongilla (Stratospongilla) tonolli Bonetto \& Ezcurra de Drago, 1968: 435 fig. IV; Volkmer-Ribeiro, 1970: 441.

Oncosclera tonolli; Volkmer-Ribeiro, 1981: 89.

Holótipo e parátipos depositados no Instituto Nacional de Limnologia, Santa Fé, Santo Tomé, Argentina.

Material examinado. MCN-POR 6286, 6370, rio Piquiri, Porto Bananeira, Campina da Lagoa, Paraná, Brasil, 25.XI.04, C. Volkmer Ribeiro leg.

Descrição. A esponja ocorreu com crostas muito delga- 
das e pequenas ou apenas grupos de gêmulas sobre os substratos rochosos (Figs 29-30). Esponja viva de cor marfim e consistência frágil. Esqueleto constituido por uma trama irregular, cerrada, das megascleras, sem distinção de fibras, determinando malhas de formas e tamanhos variados. Megascleras estrôngilos de lisos a micropontuados, curtos, levemente curvos, raras oxeas presentes Gemoscleras estôngilos curtos, geralmente lisos, raramente micropontuados, variando em curvaturas e expansão das extremidades, geralmente medianamente inflados e tendendo para formas bizarras ou esféricas (Figs 31-32). Gêmulas relativamente pequenas, não muito abundantes, em extratos basais cobertos pelo esqueleto ou isoladas nas reêntrancias das pedras.

Habitat. O habitat agora descrito confere com o registrado originalmente para a espécie, caracterizado-se por substratos rochosos em águas turbulentas.

Distribuição. O presente registro amplia a distribuição da espécie da localidade de Salto Grande, Rio Uruguai, Provincia de Entre Rios, Argentina, extendendo-a ao Rio Piquiri e, portanto a Bacia do Paraná, no Estado do Paraná, Brasil.

Comentários. A identificação dos espécimes do rio Piquiri foi feita sobre as características das gemoscleras, que se conformaram plenamente à descrição original, uma vez que as megascleras, na sua maioria, ficaram dentro das megascleras oxeas e anfistrôngilos menores, ilustrados na descrição original. Atribuise esse aspecto ao fato dos poucos exemplares coligidos no Piquiri mostraram crostas muito tênues, indicando exemplares jovens ou sub-desenvolvidos. Confirma-se aqui o status específico de O. tonolli, já que a espécie, originalmente descrita para o rio Uruguai apresenta agora na bacia do rio Paraná novamente as características originais. A espécie mostra-se próxima a $O$. navicella, distinguindo-se porém dessa, pelas mesgascleras, estrôngilos pouco curvados e pelas gemoscleras, também estrôngilos, apresentando formas bizarras geralmente infladas na parte central.

\section{DISCUSSÃO E CONCLUSÕES}

A assembléia de esponjas agora detectada no Rio Piquiri é a primeira, das já registradas para substratos rochosos de rios da America do Sul, que inclui a presença de S. brasiliensis, razão de sua peculiaridade. Bonetto \& Ezcurra de Drago (1964, 1969, 1970) e Ezcurra de Drago (1966), realizaram investigações sobre as assembléias de esponjas que ocupam esses substratos nos cursos médios dos rios Paraná e Uruguai ou seus pequenos contribuintes na Argentina, as prospecções havendo incidido sobre as cotas de maior exposição dos fundos, em épocas de secas prolongadas. Esses levantamentos mostraram uma abundância inusitada de poríferos, quando comparadas às estudadas no hemisfério norte. O mais detalhado desses estudos, no que tange à abordagem metodológica (BonetTo \& Ezcurra DE Drago 1970), revelou assembléias distintas, conforme o tipo de fluxo e de substrato (rochas maiores ou menores, fundos pedregosos, com ou sem cobertura de perifiton ou podostemáceas), a riqueza em espécies variando bastante, conforme o habitat, sendo maior em trechos com águas mais profundas e menos turbulentas, chegando então a composições com 4-5 espécies/gêneros. Ainda na Bacia do Paraná, Batista \& Volkmer-Ribeiro (2002) com prospecções no curso superior do rio Paraná e do Paraguai, dirigidas aos substratos rochosos expostos por ocasião dos barramentos de rios para formação de lagos de hidrelétricas, revelaram assembléias compostas por até seis espécies de esponjas, nas tres famílias (Spongillidae, Potamolepidae e Metaniidae). BATISTA et al. (2003) amostraram essa fauna em dique rochoso do leito do rio Araguaia. Volkmer-Ribeiro \& Pauls (2000) por sua vez, aportam os primeiros levantamentos de esponjas em tratos rochosos da bacia do Orinoco. Em razão do exposto é de prever-se que a assêmbleia de esponjas agora detectada no rio Piquiri deva conter um número maior de espécies já que os levantamentos efetuados tiveram característica pontual. Os trabalhos acima referidos indicam ainda sempre a predominância de alguns gêneros (Oncosclera, Drulia Gray, 1867, Corvospongilla Annandale, 1911, Trochospongilla Vejdovsky, 1883) e mesmo espécies (O. navicella, D. uruguayensis, C. seckti, T. repens) de norte a sul do continente. Em que pesem os amplos esforços de amostragem já exercidos, $S$. brasiliensis foi detectada até agora somente na bacia do rio Paraná e no Brasil. O presente registro assume importância considerável, por constituir o único que atesta, com dados georeferenciados, a existência atual de população exuberante da espécie. Essa, aliada aos aspectos particulares da assembléia detectada, conferem ao Rio Piquiri, no trecho estudado, condições de águas naturais ou muito próximas dessas. Tomando em consideração o fato de que $S$. brasiliensis integra a lista recente da fauna ameaçada do Brasil (Brasil 2004), aliado à vitalidade que a população detectada apresenta no local, integrando uma assembléia, que acredita-se ainda não inteiramente levantada, é de todo recomendável que se indique a preservação do Rio Piquiri na área considerada, já eleita pela população local para suas atividades de lazer. Aos argumentos a favor dessa indicação deve somar-se à beleza cênica do ambiente, que os autores não podem furtar-se de registrar, por haverem dela usufruído nas atividades de campo.

\section{AGRADECIMENTOS}

Os autores agradecem a Elaine Antoniassi Luiz, do Integrado Colégio e Faculdade de Campo Mourão, pela indicação de ocorrência e aporte do primeiro espécime de $S$. brasiliensis do Rio Piquiri; a Valdir Alves, Faculdade de Ciências e Letras de Campo Mourão, PR, pelo apoio prestado em campo. À Dra. Inés Ezcurra de Drago, Instituto Nacional de Limnologia, Santa Fé, Argentina, pela confirmação da identificação dos materiais de O. tonolli; a Vanessa de Souza Machado bolsista BIC-FAPERGS no MCN da FZB, pelas preparações laboratoriais do material espongológico, a Manoel Luiz Nunes, MCN da FZB, pelas análises do conteúdo de Sílica na água e ao Integrado Colégio e Faculdade pelo apoio na realização das fotografias em microscopia ótica. A autora sênior agradece ao CNPq pela bolsa de produtividade em pesquisa e respectivo Grant concedidos. 


\section{REFERÊNCIAS BIBLIOGRÁFICAS}

American Public Health Association. 1992. Standard methods for the examination of water and wastewater. Washington, APHA, $18^{\text {th }}$ ed., 905p.

Batista, T.C.A. \& C. Volkmer-Ribeiro. 2002. Comunidades de esponjas do curso superior dos rios Paraná (Goiás) e Paraguai (Mato Grosso), Brasil, com redescrição de Oncosclera schubarti (Bonetto \& Ezcurra de Drago). Revista brasileira de Zoologia, Curitiba, 19 (1): 123-136.

Batista, T.C.A.; C. Volkmer-Ribeiro; A. Darwich \& L.F. Alves. 2003. Freshwater sponges as indicators of floodplain lake environments and of river rocky bottoms in Central Amazonia. Amazoniana, Kiel, 17 (3/4): 525-549.

BonetTo, A.A. \& I. Ezcurra De Drago. 1964. La fauna bentônica de algunas Aguas Rápidas del Paraná Medio. Physis, Buenos Aires, 24 (68): 311-316.

Bonetto, A.A. \& I. Ezcurra de Drago. 1967. Esponjas del noreste argentino. Acta zoologica Lilloana, San Miguel de Tucumán, 23: 331-348.

Bonetto, A.A. \& I. Ezcurra de Drago. 1968. El gênero Spongilla Lamarck en el rio Uruguay. Physis, Buenos Aires, 27 (75): 429-436.

Bonetto, A.A. \& I. EzCurRa DE Drago. 1969. Algunas caracteristicas del bentos en los Saltos del Rio Uruguay, con especial referência a la Ecologia de los Poriferos. Physis, Buenos Aires, 28 (77): 359-369.

Bonetto, A.A. \& I. Ezcurra de Drago. 1970. Esponjas de los afluentes del Alto Parana en la Provincia de Misiones. Acta zoologica Lilloana, San Miguel de Tucumán, 27: 37-58.

Boury-Esnault, N. \& K. Rützler. 1997. Thesaurus of Sponge Morphology. Washington, Smithsonian Contributions to Zoology, 117p.

BRASIL. 2004. Instrução Normativa n ${ }^{\circ}$ 5, de 21 de maio de 2004. Diário Oficial da República Federativa do Brasil, Brasilia, 28 de maio de 2004, seção 1, p. 136-142.

CARTER, H.J. 1881. History and classification of the known species of Spongilla. Annals and Magazine of Natural History, London, 5 (7): 77-107.

Ezcurra de Drago, I. 1966. Notas preliminares acerca de la fauna bentonica de las cuencas isleñas del Parana Medio. Physis, Buenos Aires, 26 (72): 313-330.

Ezcurra de Drago, I. 1978. Una nueva especie de Stratospongilla Annandale, 1909, para Sudamerica (Porifera, Spongillidae). Neotropica, La Plata, 24 (72):106-110.

Justus, J. DE O. 1990. Hidrografia, p. 185-218. In: IbGE (Ed.). Geografia do Brasil, Região Sul. Rio de Janeiro, Intituto Brasileiro de Geografia e Estatística, II+419p.

Kaul, P.F.T. 1990. Geologia, p. 29-54. In: IbGe (Ed.). Geografia do Brasil, Região Sul. Rio de Janeiro, Intituto Brasileiro de
Geografia e Estatística, II+419p.

Leite, P.F. \& R.M. Klein. 1990. Vegetação, p. 113-188. In: IBgE (Ed.). Geografia do Brasil, Região Sul. Rio de Janeiro, Intituto Brasileiro de Geografia e Estatística, II+419p.

MaAck, R. 2002. Geografia Física do Estado do Paraná. Curitiba, Imprensa Oficial do Paraná, III+438p.

Manconi, M. \& R. Pronzato. 2002. Surb-order Spongillina subord. nov.: freshwater sponges, p 921-1019. In: J.N.A. HOOPER \& R.W.M. van SOEST (Eds). Systema Porifera: a guide to the classification of sponges, New York, Kluwer Academic, Plenum Publisher.

Moser, J. M. 1990. Solos, p. 85-112. In: IbGe (Ed.). Geografia do Brasil, Região Sul. Rio de Janeiro, Intituto Brasileiro de Geografia e Estatística, II+419p.

Nimer, E. 1990. Clima, p. 151-158. In: Ibge (Ed.). Geografia do Brasil, Região Sul. Rio de Janeiro, Intituto Brasileiro de Geografia e Estatística, II+419p.

PARANÁ. 1990. Atlas do Estado do Paraná. Curitiba, Secretaria de Estado da Agricultura e do Abastecimento, 74p.

Pinheiro, U.S.; E. Hajdu \& M.E. Caballero. 2003. Três novos registros de esponjas (Porifera, Demospongiae) para águas continentais do Estado de São Paulo. Boletim do Museu Nacional, Nova Série, Zoologia, Rio de Janeiro, (498): 114.

TAVAres, M.C.M. \& C. Volkmer-Ribeiro. 1997. Redescrição das esponjas de água doce Oncosclera navicella (Carter, 1881) (Potamolepidae) e Spongilla spoliata Volkmer-Ribeiro \& Maciel, 1983 (Spongillidae). Biociências, Porto Alegre, 5 (1): 97-111.

VolKmer-Ribeiro, C. 1970. Oncosclera - a new genus of freshwater sponges (Porifera-Spongillidae) with redescription of two species. Amazoniana, Kiel, 2 (4): 435-442.

Volkmer-Ribeiro, C. 1981. Porifera, p. 86-95. In: S.H. Hurlbert; G. Rodrigues \& N.D. SAntos (Eds). Aquatic Biota of Tropical South America. San Diego State University, San Diego, California.

Volkmer-Ribeiro, C. \& R. De Rosa-Barbosa. 1978. A new genus and species of Neotropical freshwater sponges. Iheringia, Série Zoologia, Porto Alegre, 52: 103-107.

Volkmer-Ribeiro, C. \& De Rosa-Barbosa, R. 1979. Neotropical freshwater sponges of the family Potamolepidae Brien, 1967, p. 503-511. In: C. Levi \& N. Boury-Esnault (Eds). Biologie des Spongiaires. Paris, Colloque Internatiounaux du C.N.R.S., vol. 291.

Volkmer-Ribeiro, C. \& S.M. Pauls. 2000. Esponjas de Agua Dulce (Porifera, Demospongiae) de Venezuela. Acta Biologica Venezuelica. Caracas, 20 (1): 1-28.

Volkmer-Ribeiro, C. \& B.J. Turce. 1996. SEM analysis of silicous spicules of a freshwater sponge indicate paleoenvironmental changes. Acta Microscopica, Rio de Janeiro, 5 (6): 186-187.

Recebido em 01.IV.2005; aceito em 05.XI.2005. 